\title{
Knockouts of Src-family kinases: Stiff bones, wimpy $T$ cells, and bad memories
}

\author{
Clifford A. Lowell ${ }^{1}$ and Philippe Soriano ${ }^{2}$ \\ ${ }^{1}$ Department of Laboratory Medicine, University of California, San Francisco, California 94143 USA; ${ }^{2}$ Division of Molecular \\ Medicine, Fred Hutchinson Cancer Research Center, Seattle, Washington 98104 USA
}

It has now been 20 years since the viral oncogene $\mathrm{v}$-Src was shown to be derived from a normal cellular gene, c-src (Stehelin et al. 1976). During that time period, much has been learned about the function of Src and related Src-family kinases (SFKs) in cell lines and in a variety of organisms. As Src was initially identified as the product of a proto-oncogene, SFKs have naturally been believed to play an important role in regulating cell growth and differentiation. Consistent with this viewpoint, SFKs are often activated following growth stimulation, and the activity of the kinases is regulated during progression through the cell cycle. Much more has been learned from biochemical studies, with the identification of multiple Src substrates in Src-transformed cells. Many of these substrates are associated with the cytoskeleton, suggesting that SFKs may regulate cytoskeletal organization. Nonetheless, these observations fall short of uncovering the role of these kinases in normal physiological processes. The advent of loss-of-function studies in the mouse has provided new insights into the biology of SFKs. This review attempts to summarize these observations, as mice carrying mutations in all of the known SFK members have now been generated.

Src and its relatives encode a group of closely related nonreceptor protein tyrosine kinases (for a recent comprehensive review, see Brown and Cooper 1996). SFKs are also evolutionarily conserved, with members found in both vertebrates and nonvertebrates. In the mouse, there are eight SFK members (Src, Fyn, Yes, Lyn, Hck, Fgr, Blk, and Lck). One additional SFK, Yrk, has been identified in chicken (Sudol et al. 1993), but the corresponding gene has not yet been found in mammals. All of these kinases share a common structure (Fig. 1): a short amino-terminal membrane anchor or $\mathrm{SH} 4$ region ( $\mathrm{SH}$ for Src homology); a unique domain characteristic of each individual kinase; an SH3 domain, which binds proline-rich sequences; an SH2 domain, which binds phosphotyrosine-containing peptide sequences; a catalytic or SHl domain, which encodes kinase activity; and a short carboxy-terminal tail containing the major regulatory tyrosine residue. All family members show extensive sequence homology in the $\mathrm{SH} 1, \mathrm{SH} 2$, and $\mathrm{SH} 3$ domains and in the $\mathrm{SH} 4$ region, but diverge in the unique domain.

SFK members show a variety of expression patterns
(Table 1). In the mouse, Src, Fyn, Yes, and Lyn are found in a broad range of tissues with especially high levels in hematopoietic and neural cells. Although the expression pattern of these kinases overlaps to a large extent, they are not all coexpressed in any given cell type. Nonetheless, it is probable that many cell types will produce at least one of these four kinases. These four kinases are also expressed during early embryonic development, with expression levels of src being sharply up-regulated as the nervous system develops (Cartwright et al. 1988). The four hematopoietic-restricted kinases, Hck, Fgr, Lck, and Blk, are found in a variety of lineages. In general, myeloid cells coexpress Hck, Fgr, and Lyn, whereas $T$ cells express predominately Lck and Fyn, and B cells express mainly Lyn, Blk, Fyn, and Fgr. Many of the SFKs are expressed as different isoforms as a result of alternative splicing. There are two neuronal-specific forms of Src, which are produced by alternative splicing of small exons in the SH3 domain (Martinez et al. 1987; Pyper and Bolen 1990). The fyn gene shows alternative splicing of the seventh exon encoding the kinase domain, yielding a hematopoietic specific isoform-Fyn(T)-and another isoform expressed in other tissues, which has been referred to as the brain isoform-Fyn $(\mathbf{B})$ - Cooke and Perlmutter 1989). There are also two coexpressed isoforms of the Lyn kinase, which are the result of alternative splicing within the unique domain (Stanley et al. 1991; Yi et al. 1991). Two isoforms of Hck, differing in their SH4 amino-terminal domains, are produced as a result of alternative translational initiation (Lock et al. 1991).

The subcellular localization of SFKs is tightly regulated, providing a significant clue as to their function. Myristoylation of the second amino acid, a glycine, is required for tethering SFKs to membranes; membrane association is required for function (Resh 1994). In addition, several SFKs are palmitoylated at cysteines within the SH4 region, presumably resulting in increased stabilization at the membrane (Robbins et al. 1995). SFKs have been found in association not only with the plasma membrane, but with endosomes, the rough endoplasmic reticulum (RER), secretory vesicles, and caveolae (Kaplan et al. 1992; Robbins et al. 1995). In bone marrow and peritoneal macrophages, a significant proportion of Fgr 


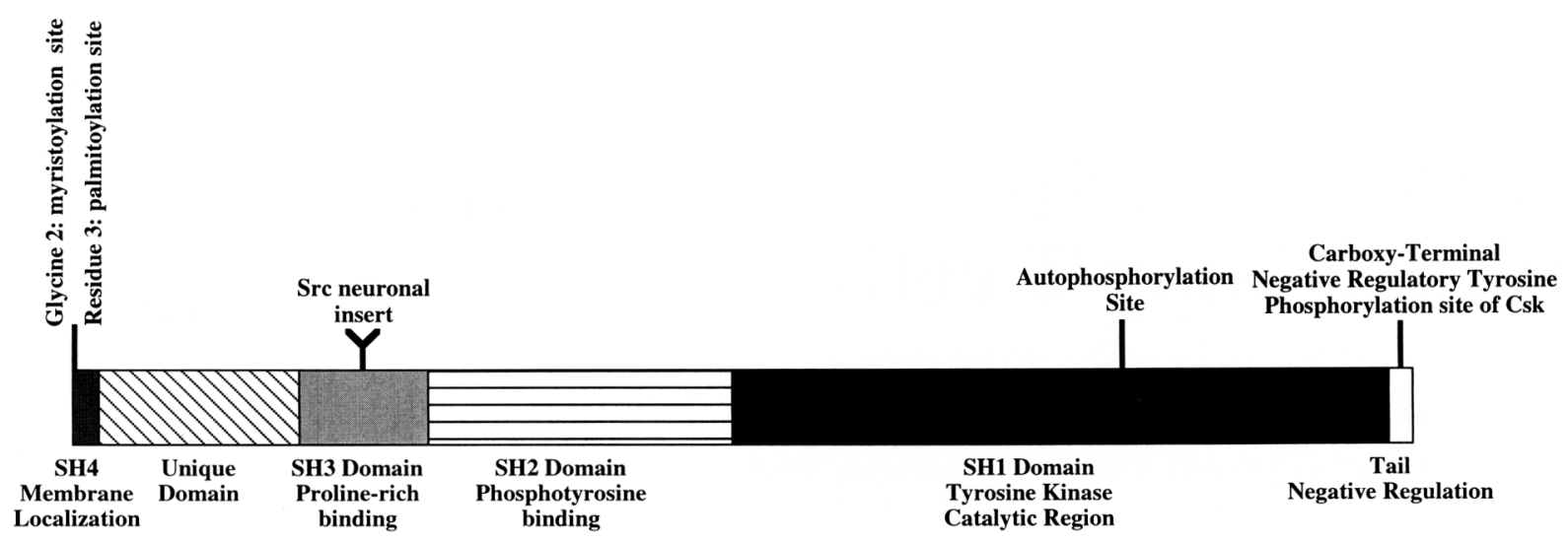

Figure 1. Domain structure and key regulatory sites for Src-family kinases.

has been found in the nucleus, but this has not been observed with other members of the family (C.A. Lowell, unpubl.).

Within membranes, SFKs are believed to associate with the cytoplasmic tails of trans-membrane receptors that lack kinase domains and thus serve to transduce signals from these receptors. Engagement of a receptor can lead to enzymatic activation of the associated SFK and initiation of a signal transduction cascade. The first identified example of such an interaction was that of the cytoplasmic tail of CD4 or CD8 with Lck in T cells (for review, see Weil and Veillette 1996). As CD4 binds to the unique domain of Lck and does not associate with other SFKs, interactions of this type might be nondegenerate and essential for CD4-mediated T-cell stimulation. A diverse spectrum of receptor-mediated stimuli has now been shown to result in activation of SFKs; in many cases, SFKs are also found to be physically associated with some of these receptors. Ligation of receptors for growth factors (PDGF, EGF), cytokines (IL-2, IL-3, IL-6), antigens, antibodies (Fc receptors), G protein-coupled receptors (thrombin, chemoattractants), and adhesion re- ceptors (integrins) have all been shown to result in activation in one or more SFKs in many different cell types (for review, see Erpel and Courtneidge 1995). Additionally, activation of several SFKs has been observed in response to oxidant stress (UV treatment) and during mitosis.

The signaling pathways initiated by activation of SFKs are just as diverse. SFKs have been shown to initiate signaling through the Ras pathway, to activate phosphatidylinositol kinases, to phosphorylate proteins involved in cytoskeletal reorganization, and perhaps to directly activate transcription factors such as $\mathrm{c}-\mathrm{Myc}$ that are required for mitogenesis (Barone and Courtneidge 1995). A great deal of redundancy between SFKs is observed in all of these pathways; often a single kinase is activated by multiple different stimuli to the same cell type, whereas the same stimulus may activate multiple SFKs. The first documented example of this type was the association of the platelet-derived growth factor $\beta$ (PDGF $\beta$ ) receptor with Src, Fyn, and Yes, which are coexpressed in fibroblasts (Kypta et al. 1990). It is believed that such interactions are critical for proliferation in re-

Table 1. Expression patterns and mutant phenotypes of SFK members

\begin{tabular}{|c|c|c|c|}
\hline Gene & $\begin{array}{l}\text { MW protein } \\
\text { products }\end{array}$ & Expression & Phenotype of single mutant \\
\hline c-src & $\begin{array}{l}\mathrm{p} 60^{\mathrm{c}-s r c}(3 \\
\text { isoforms })\end{array}$ & $\begin{array}{l}\text { nearly ubiquitous, highest in brain, platelets, and } \\
\text { osteoclasts }\end{array}$ & osteopetrosis due to defective osteoclast function \\
\hline fyn & $\begin{array}{l}\mathrm{p} 59^{f y n(B)} \\
p 59^{f y n(T)}\end{array}$ & $\begin{array}{l}\text { brain isoform found in brain, fibroblasts, } \\
\text { endothelial cells, and keritinocytes. Thymocyte } \\
\text { form-T-cells, B-cells }\end{array}$ & $\begin{array}{l}\text { abnormal hippocampal development, defective } \\
\text { LTP, impaired memory; mild defect in } \\
\text { thymocyte signaling }\end{array}$ \\
\hline c-yes & $\mathrm{p} 62^{\text {yes }}$ & $\begin{array}{l}\text { highest in brain, fibroblasts, and endothelial cells } \\
\text { also T-cells, platelets }\end{array}$ & none observed \\
\hline lyn & $\begin{array}{l}\mathrm{p} 53^{\text {lyn }} \\
\mathrm{p} 56^{\text {lyn }}\end{array}$ & brain, B-cells, and myeloid cells & impaired B-cell function, autoimmunity \\
\hline$h c k$ & $\begin{array}{l}\mathrm{p} 59^{h c k} \\
\mathrm{p} 61^{h c k}\end{array}$ & myeloid cells & none observed \\
\hline$c-f g r$ & $\mathrm{p} 58^{\mathrm{c}-f g x}$ & myeloid cells, mature B-cells & none observed \\
\hline blk & p56 $6^{b l k}$ & B-cells & none observed \\
\hline lck & $\mathrm{p} 56^{1 c k}$ & T-cells, NK cells & $\begin{array}{l}\text { block in T-cell development; impaired TCR } \\
\text { signaling }\end{array}$ \\
\hline
\end{tabular}


sponse to PDGF (Twamley-Stein et al. 1993). The absence of one family member, however, may not eliminate mitogenic responses if the other family members are able to compensate. Interpretation of the physiologically significant functions of the SFKs is therefore quite complex, as these and many other studies suggest that SFKs may have both unique and redundant functions in different cell types. In this regard, careful examination of the above signaling pathways in animals, tissues, and cells genetically devoid of SFKs becomes critical.

The subcellular localization of SFKs and the regulation of their activity by phosphorylation are intimately interconnected. Phosphorylation/dephosphorylation of the main regulatory tyrosine, Y527 in chicken Src, controls the specific activity of $\mathrm{Src}_{\text {; }}$ phosphorylation of Y527 leads to a decrease in Src activity by 10 - to 20 -fold. Several lines of evidence indicate that this inhibition of activity is caused by intramolecular binding of the carboxy-terminal phosphorylated Y527 to the SH2 domain, and maintenance of the protein in this closed conformation requires the SH3 domain (for review, see SupertiFurga 1995). The absence of this regulatory tyrosine is the main feature distinguishing v-Src from c-Src; v-Src is rendered constitutively active because of its inability to form the closed conformation by intramolecular association with the SH2 domain. Similarly, mutation of Y527 to the nonphosphorylated amino acid phenylalanine blocks the intramolecular folding of Src and constitutively activates the kinase, rendering the protein transforming. Both the Csk (Nada et al. 1991; Bergman et al. 1992) and Ctk/Ntk (Chow et al. 1994; Klages et al. 1994) kinases have been shown to phosphorylate SFKs at the regulatory carboxy-terminal tyrosine. Although phosphorylation of this tyrosine can also occur in cells devoid of Src activity (Thomas et al. 1991), autophosphorylation or phosphorylation by another SFK cannot be ruled out. Hence, these two kinases are thought to serve as the main down-regulators of SFK activity. Dephosphorylation of Y527 by a variety of protein-tyrosine phosphatases (such as SHP-1 or the CD45 protein) up-regulates SFK activity (for review, see Dixon 1995).

Cells that express activated variants of Src are transformed and exhibit an altered cytoskeletal architecture. In these cells, but not in normal cells, Src is found predominantly in altered focal adhesions termed podosomes or rosettes (Rohrschneider 1980; Kaplan et al. 1994). Fo$\mathrm{cal}$ adhesions are structures that serve to attach the cell to the extracellular matrix. In these locations, SFKs have been found to phosphorylate a number of substrates, which are ultimately associated with the actin cytoskeleton or focal adhesions, or are implicated in cell-cell adhesion. Here again, various SFKs may have unique or redundant roles in regulating cytoskeletal organization (Thomas et al. 1995). Although it is believed that SFKs may be phosphorylating a number of substrates directly, they may also have kinase-independent roles if they serve as adaptors through their $\mathrm{SH} 2$ and $\mathrm{SH} 3$ domains.

This brief introduction lays down the foundations for the genetic studies. SFKs may have functions that are both unique and redundant, and they may act through mechanisms dependent or independent of kinase activity. These considerations might help us to understand the phenotypes associated with loss of function or activation of various family members. Gene-targeting technology has now led to disruptions of all known family members in the mouse.

\section{Role of Src-family kinases in bone development}

The first SFK to be disrupted was Src (Soriano et al. 1991). The main phenotype associated with this mutation is osteopetrosis, a bone remodeling disease in which excess bone accumulates as a result of defective osteoclast activity. This mutation manifests itself by the failure of incisors to erupt, and the mutants have a very reduced survival rate after weaning. However, animals maintained on a soft food diet have been found to survive for at least a year and, on rare occasions, can reproduce (C.A. Lowell and P. Soriano, unpubl.). In $s \mathrm{C}^{-}$mice, osteoclasts are present at a normal density on the bone surface, but because there is more total bone, there are increased numbers of osteoclasts in mutants compared to wild type. These osteoclasts fail to form a normal ruffled border, the area of the cell that normally contacts and resorbs bone (Boyce et al. 1992). The defect is thus a failure in osteoclast function rather than formation. Transplantation experiments indicate that the defect is associated with the osteoclasts themselves, rather than attributable to a defect of osteoblasts or stromal cells in the bone microenvironment, as normal bone growth can be restored in $\mathrm{src}^{-}$mice by fetal liver transfers from wild-type donors (Lowe et al. 1993). It turns out that Src is highly expressed in osteoclasts (Horne et al. 1992; Lowell et al. 1996b), a fact that was unknown when the Src knockout phenotype was first published.

There are now six mutations that lead to osteopetrosis in the mouse, four of which are in known genes. The first described mutation, op (for osteopetrosis), is caused by a point mutation in the CSF1 gene (Wiktor-Jedrzejczak et al. 1990; Yoshida et al. 1990). Hence, bone marrow stromal cells fail to produce CSF1, leading to a block in osteoclast differentiation. As the CSF1 receptor, c-Fms, is expressed on osteoclasts, and multiple Src family kinases can associate with the CSF1 receptor (Courtneidge et al. 1993), it is possible that op and src act in the same pathway. The disruptions of two other genes, fos (Johnson et al. 1992; Wang et al. 1992) and a basic-leucine zipper/helix-loop-helix (bZIP-HLH) transcription factor in the micropthalmia (mi) locus (Hemesath et al. 1994), also lead to osteopetrosis. In the case of fos, the phenotype is much more severe than in $\mathrm{src}^{-}$mice, leading to a significant amount of extramedullary hematopoiesis. Mutations in two other unidentified genes, grey lethal (gl) and osteosclerotic (oc), also lead to osteopetrosis (Green 1989), but the mutated genes have not been identified.

Because osteoclasts are terminally differentiated cells, it is difficult to perform extensive cell biological assays to understand the nature of the defect associated with 
the loss of Src. There at least two general possibilities, however, that prompt speculation. First, osteoclasts may be considered as secretory cells, which digest the bone matrix by releasing hydrolases and acidifying the bone microenvironment. As Src had been found to be associated with endosomal membranes, it is possible that it is required in vesicle trafficking and secretion. It is unclear, however, how this would explain the changes in morphology that are found in the mutant osteoclasts. Alternatively, Src may be regulating cytoskeletal organization and adhesion to the extracellular matrix (ECM).

Src is not the only SFK to be expressed in osteoclasts, however (Horne et al. 1992; Lowell et al. 1996b). Mouse osteoclasts exhibit high levels of Hck and Fgr as well as Src. Moreover, the fact that osteopetrosis in the $\mathrm{src}^{-}$ mice is not as severe as in the fos mutants suggests that other kinases may function in the same signaling pathways as Src within osteoclasts. In support of this interpretation, $h c^{-} s r c^{-}$double-mutant mice exhibit significantly more severe osteopetrosis than $\mathrm{src}^{-}$single mutants (Lowell et al. 1996b). Hck protein levels are increased in $\mathrm{src}^{-}$osteoclasts, suggesting that higher levels of Hck partially compensate for the absence of Src, resulting in a less severe osteoclast defect. The observation that Src has a higher specific kinase activity in osteoclasts (Lowell et al. 1996b) than in other cells, whereas Hck kinase activity does not vary, may explain why osteopetrosis is associated with loss of function of Src but not Hck.

Mice mutant for both Src and Fyn or Src and Yes die at birth, with no distinguishable feature except that the double mutants are smaller than their single mutant, heterozygous, or wild-type littermates (Stein et al. 1994). Although these observations are consistent with the hypothesis that SFKs may be playing overlapping roles during development, the increase in severity of the doublemutant phenotype is more difficult to interpret than in $h c k^{-} \mathrm{src}^{-}$mice, as the additive effect of two mutations has not been examined in a single cell type.

\section{Role of Src-family kinases in neural development}

Src is expressed in neural tissues in three isoforms, two of which are derived from neuronal-restricted splicing of additional exons into the SH3 domain. The pattern of expression of Src in the brain has been analyzed by immunohistochemistry (Sugrue et al. 1990), as well as by in situ hybridization (Ross et al. 1988). Src is found in a variety of different neurons, particularly in the mesencephalon, cerebellum, pons, medulla, hippocampus, and olfactory bulb. No overt phenotype has been associated with the src mutation in neural tissues. This observation raises the possibility that Src function may be redundant with that of other family members in the brain.

Three other SFK members, Fyn, Yes, and Lyn, are produced in neural tissues during development and in the adult. The pattern of expression of fyn has been examined in mice in which the fyn gene was disrupted with a $\beta$-galactosidase gene (Yagi et al. 1993b), as well as by in situ hybridization (Umemori et al. 1992). fyn is ex- pressed at early stages of development in the neural tube and rhombomeres and later in the marginal layer of the neural tube, as well as in dorsal root filaments of neural crest origin. Yes has also been found to be highly concentrated in neural tissues, particularly in the Purkinje cells of the cerebellum (Sudol et al. 1988), whereas Lyn is found in the granular cells of the cerebellum and vascular endothelium throughout the brain (Umemori et al. 1992; Achen et al. 1995).

Mutations in Fyn, Yes, and Lyn have been generated, but to date the effect of disrupting Lyn on neural structures has not been documented (Hibbs et al. 1995; Nishizumi et al. 1995). A mutation in the yes gene (Stein et al. 1994) has been generated with no overt phenotype in the resulting mice. Although this mutation appears to completely block Yes protein production in the brain and several adult tissues (P. Stein, unpubl.), a catalytically inactive form of the protein (which lacks kinase domain sequences encoded by the mutated exon) is found in fibroblasts (Thomas et al. 1995). It is unclear whether this partial peptide provides any normal Yes function in vivo.

fyn ${ }^{-}$mutant mice (Stein et al. 1992), in contrast, show defects in the hippocampus (Grant et al. 1992). In these mice, there is an increase in the number of granule cells in the dentate gyrus and pyramidal cells in the CA3 region. These mice show defects in long-term potentiation (LTP), although synaptic transmission and two forms of synaptic plasticity, paired-pulse facilitation and post-tetanic potentiation, remain normal. Associated with this deficit in LTP, mutant mice show impaired spatial learning in a Morris water maze. The defects appear to be specific, as $\mathrm{src}^{-}, \mathrm{yes}^{-}$, and $a b 1^{-}$mice do not show such symptoms. Recent results suggest that only older animals show an LTP defect and that this is not attributable to the abnormal architecture of the hippocampus, because expression of a fyn transgene from a CamKII promoter in the forebrain rescues the LTP defect in fyn ${ }^{-}$ mice, but does not affect the hippocampal structure (E. Kandel, pers. comm.). Neuronal cells from $f y^{-}$mice up-regulate Src activity, especially in Triton X-100 insoluble cytoskeletal fractions, suggesting that there is partial compensation for the loss of Fyn activity by changes in activity and/or subcellular redistribution of Src (Stein et al. 1994; Grant et al. 1995).

Additional defects have been observed with mice carrying another mutation in the fyn gene. In these mice, a $\beta$-galactosidase gene has been inserted in-frame downstream of the SH3 domain (Yagi et al. 1993b). Homozygous fyn ${ }^{\text {lac } Z}$ mutant females failed to nurse litters of homozygous mutant pups but were able to nurse mixed litters, presumably because wild-type or heterozygous pups could activate milk secretion from lactating nipples (Yagi et al. 1993a). Such defects, however, have not been observed with mice carrying a null mutation in the gene (Stein et al. 1992), raising the possibility that the defects observed in the fyn ${ }^{\text {Iacz }}$ mutants are associated with the continued presence of the unique or SH3 domains. In addition, the fyn ${ }^{\text {lacz }}$ mutants exhibit a reduced level of myelination, although myelin sheaths could be detected by electron microscopy in these mice (Umemori et al. 
1994). Deficits in myelination have not been checked for in fyn null mutant animals.

The effect of mutations in several SFKs becomes much more apparent when neurons are cultured in vitro, $s r c^{-}$ cerebellar neurons extend neurites to the same extent as wild-type, $\mathrm{fyn}^{-}$, or yes ${ }^{-}$neurons when cultured on laminin, whereas the length of the neurites is reduced when cultured on the neural cell adhesion molecule L1 (Ignelzi et al. 1994). Conversely, fyn ${ }^{-}$cerebellar or dorsal root ganglia neurons fail to extend neurites when cultured on cells transfected with neural cell adhesion molecule 140 (NCAM140), whereas no defect is observed with src $^{-}$, yes $^{-}$, or wild-type neurons (Beggs et al. 1994). Coimmunoprecipitation experiments from extracts of either mouse cerebellum at postnatal day 4, transfected COS cells, and transfected B35 rat neuroblastoma cells show that NCAM140 but not NCAM180 associates with Fyn. Neither NCAM isoform associates with Src. Also, triggering NCAM140 on B35 neuroblastoma cells with antibodies against the NCAM extracellular domain transiently activates Fyn kinase activity (H.E. Beggs and P.F. Maness, pers. comm.). These observations support the conclusion that NCAM and L1 activate distinct SFKs, although it has been suggested that both cell adhesion molecules might also signal through a common tyrosine kinase, the fibroblast growth factor (FGF) receptor (Williams et al. 1994). These results may account for different growth-cone morphologies and adhesive contacts seen on the two different substrata (Burden-Gulley et al. 1995).

\section{Role of Src-family kinases in lymphoid development}

There is a great deal of overlapping expression of SFKs in lymphoid cells: $T$ cells express Lck and Fyn, whereas mature B cells express Lyn, Blk, Fyn, Hck, and Fgr [immature B cells lack Fyn and Fgr (Wechsler and Monroe 1995)]. Therefore, the effect of any single mutation may be confounded by coexpression of other family members. The SFK mutation studied most intensively has been the lck knockout. Thymic T-cell development, which is characterized by the progression from $\mathrm{CD} 4^{-} \mathrm{CD} 8^{--}$double-negative $(\mathrm{DN})$ to $\mathrm{CD} 4{ }^{+} \mathrm{CD} 8{ }^{+}$double-positive (DP) to $\mathrm{CD}^{+}{ }^{+}$and $\mathrm{CD} 8{ }^{+}$single-positive (SP) mature T cells, is significantly blocked in $1 c k^{-}$mutants at the DN-DP transition. As a result, $l c k^{-}$mice manifest thymic atrophy with $1 / 10$ the normal number of cells because of a reduction in $\mathrm{CD} 4{ }^{+} \mathrm{CD} 8{ }^{+} \mathrm{DP}$ cells and a complete absence of $\mathrm{CD}^{+}{ }^{+}$or $\mathrm{CD} 8{ }^{+}$SP cells (Molina et al. 1992). Outside the thymus, $5 \%-10 \%$ of normal numbers of mature $\mathrm{CD}^{+}{ }^{+}$and $\mathrm{CD} 8{ }^{+} \mathrm{T}$ cells are found; these remaining mature cells have defective antiviral responses and impaired rejection of allogenic skin grafts or tumor cells, demonstrating that Lck is required for normal T-cell activation (Molina et al. 1993; Wen et al. 1995).

Given the preponderance of studies showing a tight association between CD4 or CD8 and Lck and the importance of this association for T-cell activation (Veillette and Davidson 1992; Weiss 1993), it is surprising that the Lck deficiency probably produces its effect on
T-cell development by disruption of $T$-cell receptor (TCR) signaling early in T-cell development within DN cells. In a series of elegant genetic experiments, Perlmutter and colleagues have crossed a variety of transgenic and knockout mice to dissect the role of Lck in T-cell development. In lieu of the $1 c k$ mutation, this group has used a transgene expressing a catalytically inactive version of Lck (lckR273), which acts as a dominant-negative inhibitor of Lck and produces a block in T-cell development equivalent to, or when highly overexpressed, more severe than that seen in the $1 c k^{-}$mouse (Levin et al. 1993). To examine signaling from the TCR complex in developing T cells, 1ckR273 mice were crossed to transgenic animals expressing a rearranged TCR V $\beta$-chain. In normal T cells, the TCR V $\beta$-chain transgene mimics successful rearrangement of one TCR V $\beta$-chain allele, which prevents rearrangement of the second allele as a feedback mechanism to produce $\mathrm{T}$ cells expressing only one type of TCR. When the 1 ckR273 mutation is present, however, continued V $\beta$-chain gene rearrangement is not suppressed, indicating that the DN thymocytes fail to receive signals from the mature $\beta$-chain/CD3 complex (the pre-TCR) at the cell surface (Anderson et al. 1993). Conversely, a transgene expressing an activated form of Lck, but not Fyn or Hck, prematurely stops V $\beta$-chain gene rearrangement and drives thymocytes to the DP stage (Abraham et al. 1991; Anderson and Perlmutter 1995). Introduction of activated Lck into $\mathrm{rag}^{-}$mice, which cannot carry out TCR gene rearrangements and lack lymphocytes, restores thymus cellularity and forces maturation to DP cells, suggesting that these thymocytes are receiving positive developmental signals from the activated Lck at the membrane despite the absence of a complete TCR (Mombaerts et al. 1994). The presence of the TCR V $\beta$-chain transgene will also restore thymic cellularity in rag1- mice; however, no effect is seen in $l c k^{-}$rag $1^{-}$double mutants because of the lack of signaling from the transgenic pre-TCR (Mombaerts et al. 1994). These results indicate that activation of Lck is the primary signaling event triggered by pre-TCR expression that is required for developmental progression from the DN to DP stage.

Examination of the functional activities of the remaining peripheral $\mathrm{T}$ cells in $1 \mathrm{ck}^{-}$mice confirm that the mutation affects TCR signaling. Direct monoclonal antibody-mediated cross-linking of the TCR or CD3 in T cells from $l c k^{-}$mice results in only modest proliferative responses (Molina et al. 1992). The fact that $1 \mathrm{ck}^{-} \mathrm{T}$ cells respond at all may be attributable to the ability of Fyn to partially compensate for the Lck deficiency. Overlapping functions between these kinases is also suggested by the fact that 12-fold overexpression of the lckR273 transgene produces a much more complete block in T-cell development and complete suppression of $\mathrm{V} \beta$-chain gene rearrangement versus that seen in $1 \mathrm{ck}^{-}$mice (Wallace et al. 1995), suggesting that the dominant-negative mutant Lck protein is interfering with other SFKs. Redundancy between Lck and Fyn has now been demonstrated by generation of $\mathrm{fyn}^{-} \mathrm{Ick}^{-}$double-mutant mice (N. van Oers and A. Weiss, pers. comm.); these mice have at 
least a 100 -fold reduction in thymocytes and virtually no detectable DP cells. The actual nature of the signaling complex between the TCR and Lck has not been demonstrated in immature thymocytes, so the biochemical steps involved in this signaling pathway are undefined. Finally, NK cells from $1 \mathrm{ck}^{-}$mice appear to function normally, as assessed by proliferative responses to poly[d/IC)] or IL-2 and by normal cytotoxicity against a variety of tumor cell types (Wen et al. 1995). Therefore, despite the tight association of Lck with CD4 and CD8 in mature T cells, these genetic studies demonstrate that the primary role of Lck in T-cell development involves signaling through the pre-TCR. Likewise, as evidenced by the above studies and by generation of Lck-deficient Jurkat lines (Gupta et al. 1994), CD4-associated Lck is also required for TCR signaling in mature T cells. Interestingly, CD4-Lck chimeras have been shown to be fully active when transfected into a T-cell hybridoma line even when the kinase domain of Lck is deleted; however, activity was reduced when mutations were introduced into the SH2 domain (Xu and Littman 1993). Therefore, Lck may function to stabilize TCR signaling complexes at the cytoplasmic membrane via $\mathrm{SH} 2$ and $\mathrm{SH} 3$ interactions.

Mutation of the fyn gene has a surprisingly mild effect on T cells (Appleby et al. 1992; Stein et al. 1992). A deficiency of Fyn causes no significant defect in T-cell development or immune responses to antigenic challenge. Whereas SP thymocytes show defective responses to TCR cross-linking, as assessed by $\mathrm{Ca}^{2+}$ influx, total cellular tyrosine phosphorylation, proliferation, and IL-2 secretion, peripheral $\mathrm{T}$ cells were affected less significantly. $\mathrm{CD}^{+}{ }^{+}$and $\mathrm{CD} 8^{+} \mathrm{T}$-cell clones derived from fyn $^{-}$mice also show normal responses to stimulation through the TCR but are refractory to stimulation through GPI-linked molecules Thy-1 and Ly-6C (Lancki et al. 1995a,b). Additionally, fyn ${ }^{-}$thymocytes reactive to the Mls-la self-super antigen were not appropriately removed by negative selection, which potentially may lead to autoimmunity. No autoimmune phenonema, however, have been observed in $f_{y n}{ }^{-}$single mutants. In contrast, fyn ${ }^{-}$yes $^{-}$double-mutant animals do develop immune complex glomerulonephritis, raising the possibility that in the absence of both kinases negative selection of a more broad spectrum of self-reactive T-cells is impaired (Stein et al. 1994). These results clearly demonstrate that unlike Lck, Fyn is not required for critical TCR signaling events mediating T-cell development.

An interesting interaction between Fyn and the p125 focal adhesion kinase (Fak) has been recently shown to have a dramatic effect on T-cell development (Kanazawa et al. 1996). Fak is a nonreceptor tyrosine kinase, not of the $\mathrm{Src}^{-}$family, that localizes to focal adhesion structures and has been implicated in transducing signals from cell-surface integrins following ligation by ECM proteins (Clark and Brugge 1995; Richardson and Parsons 1995). Stable associations between Fak and Src or Fyn have been observed in fibroblast cell lines (Cobb et al. 1994). When fyn ${ }^{-}$mice are bred to $f a k^{+1-}$ mice to generate $\mathrm{fyn}^{-} \mathrm{fak}^{+1-}$ animals $\left(\mathrm{fak}^{-}\right.$homozygotes die early in gestation; Ilic et al. 1995), two-thirds of the animals suffer dramatic thymic atrophy beginning at 4 weeks of age as a result of loss of DP cells. Total thymic cell number falls to $1 / 100$ of wild-type (or compound heterozygous) animals-the remaining cells are mostly SP $\mathrm{CD}^{+}{ }^{+}$or $\mathrm{CD} 8{ }^{+}$thymocytes. The variable penetrance of the phenotype (only two-thirds of mice develop thymic depletion) may be caused by the variable expression of Fak in the heterozygous $\mathrm{fak}^{+1-}$ mutants. These results would suggest that Fyn and Fak have interactive roles in adhesive events required for T-cell development.

Mutations in SFKs that are expressed in B cells have also produced a less dramatic effect than would be expected. Given the similarities in T- and B-cell development, it was predicted that mutations in the primary B-cell SFKs, Lyn, Blk, and Fyn would result in aborted B-cell development (Anderson and Perlmutter 1995). Lyn mutations are the most recently published SFK knockouts (Hibbs et al. 1995; Nishizumi et al. 1995). A deficiency of Lyn results in a $50 \%-65 \%$ reduction in the number of peripheral B cells, as judged by B220 and IgM staining, yet normal numbers of bone marrow pre-B cell precursors are present. These peripheral B cells responded poorly to proliferative signals mediated by cross-linking of the B-cell receptor (BCR) and show defective tyrosine phosphorylation responses (Nishizumi et al. 1995). In contrast, $l y n^{-}$mice have normal antibody responses to antigenic challenge. By 3-4 months of age, however, $\mathrm{lyn}^{-}$mice develop significant splenomegaly and lymphadenopathy; concomitantly large numbers of immunoblastic cells and plasma cells, secreting primarily IgM, appear in the spleen and lymph nodes. This suggests that $l y n^{-}$mice are immunologically activated with B-cell blasts proliferating and differentiating into IgM-secreting plasma cells. As a result of this activation, lyn ${ }^{-}$mice develop extremely high levels of serum IgM and eventually develop autoimmune phenomena, including glomerulonephritis. On the basis of the development of autoimmunity, it is postulated that the mutation results in defective negative selection of autoreactive B-cell progenitors. It is unclear how defective signaling through the BCR as a result of the Lyn deficiency results in this immune dysregulation; however, it is clear that BCR signals needed to drive B-cell development cannot be entirely dependent on Lyn.

Mutations in Fyn, Blk, and Fgr have very little effect on B-cell development or function. fyn ${ }^{-}$mice do show mild reduction in IgG3 antibody secretion in response to T-independent antigens as well as impaired B-cell proliferative responses to IL-5 stimulation (Appleby et al. 1995). Responses to other cytokines, however, appear normal, and signaling events initiated by BCR crosslinking (such as tyrosine phosphorylation, $\mathrm{Ca}^{2+}$ influx and proliferation) are also normal in $\mathrm{fyn}^{-} \mathrm{B}$ cells (Sillman and Monroe 1994). In culture, fyn ${ }^{-}$pro-B cells demonstrate cell-cycle arrest following serum deprivation as a result of a failure of cytokinesis (Yasunaga et al. 1996), suggesting that Fyn may play a significant role in cytoskeletal remodeling in these cells. blk ${ }^{-}$mice have no apparent B-cell developmental or functional defects (S. 
Tarakovsky, unpubl.). blk ${ }^{-}$mutants have normal B-cell responses following BCR cross-linking in vitro, they have normal antibody responses to antigenic challenge, and they show no defects in negative selection of autoreactive B cells. B cells from $\mathrm{fgr}^{-}$and $h \mathrm{hk}^{-}$mutants also develop normally and show normal responses to BCR cross-linking in vitro (C.A. Lowell, unpubl.). Of course, the attenuated effects of mutations in SFKs on B-cell development and function can be explained by redundancy of these signaling molecules in BCR-mediated pathways. This is being tested by generation of the appropriate double or triple mutants.

\section{Role of Src-family kinases in myeloid cell development}

The major SFKs expressed in myeloid cells (neutrophils, monocytes, and macrophages) are Lyn, Hck, and Fgr (Tsygankov and Bolen 1993). These kinases have been implicated in a wide variety of intracellular signal transduction pathways in myeloid cells, including lipopolysaccharide (LPS) responses (Stefanova et al. 1993), Fc $\gamma \mathrm{R}$ signaling (Hamada et al. 1993; Wang et al. 1994), and cytokine receptor signaling (Corey et al. 1993, 1994; Anderson and Jorgensen 1995). The effects of mutations in the $h c k$ and fgr genes have been extensively studied. Single-mutant $h_{c k}^{-}$or fgr- mice show no significant defect in myeloid cell development or function; in particular, all of the above signaling pathways remain intact. Double-mutant $h c k^{-}$fgr $^{-}$mice, however, manifest a novel immunodeficiency, susceptibility to Listeria monocytogenes, not seen in single mutants (Lowell et al. 1994).

Recent biochemical evidence has implicated these kinases in integrin-mediated signaling in human neutrophils (Berton et al. 1994; Yan et al. 1995). Examination of bone marrow-derived neutrophils from $h_{c k}{ }^{-} \mathrm{fgr}^{-}$double mutants has revealed a severe defect in neutrophil functions elicited by plating cells on ECM protein-coated surfaces or by directly cross-linking surface integrins (Lowell et al. 1996a). These defects are caused by impaired cell spreading and adhesion of mutant neutrophils to ECM-coated surfaces. Biochemical evidence shows impaired tyrosine phosphorylation responses in double-mutant neutrophils following cross-linking of surface integrins by plating on ECM-coated surfaces (L. Fumagalli and G. Berton, unpubl.). Similar results have been seen with monocytes/macrophages; tyrosine phosphorylation responses are impaired following cross-linking of surface integrins in double mutant cells but not single mutants (P. Suen and C.A. Lowell, unpubl.). In an in vivo model of septic shock, double-mutant neutrophils fail to invade appropriately into inflammatory sites, suggesting that these mutations perturb adhesive interactions required for neutrophil migration. Again, single mutants are normal in this regard. Therefore, these defective adhesive events may be responsible for the immunodeficiency seen in the $h c k^{-} f g r^{-}$double mutants.

The effects of the lyn mutation on myeloid cells have not been fully explored. Preliminary results have shown no defects in LPS or Fc $\gamma \mathrm{R}$ signaling and function in $\mathrm{lyn}^{-}$ macrophages (C.A. Lowell, unpubl.). In mast cells, there is extensive biochemical evidence implicating Lyn in FceRI signaling events (Eiseman and Bolen 1992; Penhallow et al. 1995). Indeed, FceRI function appears to be abrogated completely in lyn ${ }^{-}$mice as assessed by absent passive cutaneous anaphylactic responses mediated by IgE (Hibbs et al. 1995) and absent responses of bone marrow-derived mast cells to FceRI cross-linking.

\section{Role of Src-family kinases in keratinocyte differentiation}

Primary mouse keratinocytes isolated from newborn animals can be induced into a terminal differentiation program in culture, which closely resembles what is seen in developing skin, by the addition of calcium or TPA (12O-tetradecanoylphorbol-13-acetate; Hennings et al. 1990). Rapid induction of tyrosine phosphorylation in response to calcium or TPA is required for keratinocyte differentiation in vitro (Filvaroff et al. 1990). Keratinocytes express Src, Fyn, and Yes; however, upon induction of differentiation only the Fyn kinase is activated (Calautti et al. 1995). Of the newly tyrosine-phosphorylated proteins that accumulate with initiation of differentiation, one has been identified as p80/85 cortactin, an actin-associated protein that is a known substrate of Src (Wu and Parsons 1993). The critical role of Fyn in keratinocyte development in vitro was revealed by the failure of primary cells from $\mathrm{fyn}^{-}$mice to differentiate normally in culture following calcium or TPA treatment, $f_{y n}{ }^{-}$keratinocytes developed an abnormal morphology, failed to express differentiation markers, and did not show phosphorylation on cortactin (Calautti et al. 1995). Additionally, immunofluorescence staining of skin isolated from 3-day-old $f_{y n}{ }^{-}$mice revealed decreased expression of keratin 1 and filaggrin, confirming that skin development is altered in vivo in $f_{y n}{ }^{-}$animals although the consequence of this defect is not yet known, as no other obvious skin dysfunctions have been observed. Interestingly, none of these defects was observed in yes ${ }^{-}$ or $\mathrm{src}^{-}$animals, implying that Fyn has a unique role in keratinocyte development.

\section{Regulation of Src-family kinase activity}

SFKs are negatively regulated by phosphorylation at the carboxy-terminal tyrosine Y527 in chicken Src. At least two other kinases, Csk (Nada et al. 1991) and Ctk (Klages et al. 1994), can phosphorylate several if not all SFKs at this site. Csk is broadly expressed while Ctk is found primarily in hematopoietic cells and in the brain. Mouse embryos mutant for Csk die between embryonic day 9 (E9) and E10, and exhibit a number of defects, including failure to turn around the anterior-posterior axis, impaired notochord formation, extra foldings in the neural tube, and an inability for the allantois to connect with the chorion (Imamoto and Soriano 1993; Nada et al. 1993). This latter defect most likely leads to the ensuing demise of the embryo, as nutrient and waste exchange through the placenta cannot occur /Gluecksohn-Schoen- 
heimer 1944). In mutant embryos or cell lines, all SFKs tested (Src, Fyn, and Lyn) are activated, but not to the same extent; this might reflect a different affinity of Csk for various SFK members. Phosphorylation of Src at Y527 is reduced but not eliminated and is increased significantly at Y416. Despite the fact that Y416 is believed to be an autophosphorylation site, both sites appear to be phosphorylated at least in part by another kinase when a catalytically inactive Src is introduced in double-mutant $c s k^{-}$src $^{-}$cells (A. Imamoto and P. Soriano, unpubl.). Mice carrying a targeted mutation in the $c t k$ gene have been generated but do not exhibit an overt phenotype and await further analysis (A. Imamoto, P. Soriano, J. Bolen, and R. Penhallow, unpubl.).

The loss of Csk leads to hyperphosphorylation of a number of different SFK substrates in mutant cell lines (Nada et al. 1994; Thomas et al. 1995). Csk, however, appears to have more substrates than just SFKs (Autero et al. 1994; Cance et al. 1994). To verify the involvement of SFKs in the Csk mutant phenotype, csk mutant mice were bred with src and fyn mutants. These crosses revealed an epistatic relationship between Csk and Src, but not Fyn (Thomas et al. 1995). $\mathrm{csk}^{-} \mathrm{src}^{-}$embryos developed further than $c s k$ mutant embryos and exhibited an ameliorated phenotype with respect to the turning process and completed the connection between the allantois and the chorion. Introducing the yes mutation on the csk mutant background also ameliorated the embryonic phenotype (S. Thomas, P. Soriano, and A. Imamoto, unpubl.), but this result should be interpreted with caution as the yes mutation may not be a complete null. Phosphorylation of a number of SFK substrates associated with the actin cytoskeleton or focal adhesions was elevated in $\mathrm{csk}^{-}$cells. Phosphorylation of cortactin and tensin, which associate with the actin cytoskeleton, depends primarily on Src, as phosphorylation was restored to wild-type levels in $c s k^{-} s^{-} c^{-}$cells. In contrast, phosphorylation of paxillin and Fak, which are associated with focal adhesion structures as is tensin, was reduced but not eliminated in $\mathrm{csk}^{-} \mathrm{src}^{-}$or $\mathrm{csk}^{-} \mathrm{fyn}^{-}$cells. Consistent with these observations, removal of Src significantly restored the actin cytoskeletal architecture in csk mutant cells, but removal of Src or Fyn did not suffice to normalize focal adhesion structures. Taken together, these data provide further evidence for shared and unique roles of SFK members in regulating cytoskeletal architecture, at least when they are activated.

Although tyrosine phosphorylation of a number of SFK substrates appears to be involved in regulating cytoskeletal architecture in $c s k^{-}$cells, Src may also be implicated in these processes by kinase-independent mechanisms. In csk ${ }^{-}$cells, Src is found primarily in large adhesion plaques known as podosomes (Howell and Cooper 1994), a property conferred by the amino-terminal half of Src (Kaplan et al. 1994). Interestingly, src ${ }^{-}$ fibroblasts exhibit reduced spreading on fibronectin, but this defect can be rescued by overexpression of the amino-terminal half of Src (Kaplan et al. 1995). Taken together, these observations indicate that Src can regulate cell adhesions by a kinase-independent mechanism.

\section{Src-family kinases and tumorigenesis by polyomavirus}

The transforming capability of polyomavirus $(\mathrm{PyV})$ derives from the ability of one of the viral gene products, middle T-antigen $(\mathrm{mT})$ to complex with Src, Yes, or Fyn and activate Src and Yes, but not Fyn (Courtneidge and Smith 1983; Kornbluth et al. 1987; Cheng et al. 1988). Mutants of $\mathrm{mT}$ that fail to bind Src are nontransforming (Markland and Smith 1987). To test whether this interaction is critical in vivo, two groups have taken different approaches to studying tumorigenesis by polyoma $\mathrm{mT}$ in SFK knockout mice. In one approach, newborn animals are injected intraperitoneally with a retrovirus-transducing $\mathrm{mT}$, which results in diffuse endothelial cell transformation producing numerous visceral hemangiomas (Williams et al. 1988). Injection of this retrovirus into $\mathrm{src}^{-}, \mathrm{fyn}^{-}$, or $\mathrm{yes}^{-}$animals also results in hemangioma formation in all three knockout lines, although in yes mutants fewer tumors arose after a longer latency period (Thomas et al. 1993; Kiefer et al. 1994). Biochemical analysis of cell lines derived from the hemangiomas revealed that the absence of one SFK did not impair $\mathrm{mT}$ association and activation of Src or Yes. In wild-type mice the activation of Yes was highest, suggesting that this kinase plays the dominant role in $\mathrm{mT}$ transformation and explaining why yes ${ }^{-}$mutants showed delayed formation of hemangiomas in vivo. Hence, in the endothelial cell transformation model, only a basal level of activation of either Src or Yes is adequate to initiate transformation.

In another model, $\mathrm{mT}$ is expressed in mammary epithelium as a transgene driven by the mouse mammary tumor virus (MMTV) promoter, which results in multifocal adenocarcinomas involving the entire gland in all animals (Guy et al. 1992). src ${ }^{-}$mice carrying the $\mathrm{MMTV} / \mathrm{mT}$ transgene develop only diffuse epithelial cell hyperplasia, after a long latency, with only rare tumor formation (Guy et al. 1994). In contrast, yes ${ }^{-}$mice carrying the transgene developed diffuse mammary tumors at a rate equivalent to wild type. There was no difference in Yes activity associated with $\mathrm{mT}$ in $\mathrm{src}^{-}$ versus wild-type mice or in Src activity in wild-type versus yes ${ }^{-}$tumors. Hence, in contrast to endothelial cell transformation by $\mathrm{mT}$, mammary epithelial transformation by $\mathrm{mT}$ is mediated by Src but not by Yes. This result might be attributable to different expression levels of SFKs in endothelial cells and in mammary epithelium.

\section{Conclusions and future directions}

A large body of work has provided significant insight into the role that SFKs play in signal transduction and in cell biological processes. Without those studies, the interpretation of the phenotypes observed with SFK knockouts would clearly have been much more difficult. For instance, the analysis of substrate phosphorylation in csk mutant cells was only rewarding because of the epistasis studies with SFK knockouts, which in turn would not have been undertaken were it not for the fact that Csk was known to phosphorylate SFKs and other 
targets. Similarly, the study of FceRI signaling in $1 y^{-}$ mutants was motivated by the extensive biochemical evidence implicating Lyn in this signaling pathway. The analysis of the SFK knockouts therefore represents a very good example of how biochemical studies can provide a conceptual framework for the genetic analysis. This marriage between biochemistry and genetics has gone both ways, as cell lines derived from the mutant animals clearly represent valuable reagents, for instance, to see whether an individual SFK is required for phosphorylation of a potential target or to test the activity of mutant SFKs in the absence of any endogenous protein (Thomas et al. 1991; Hunter et al. 1993; Kaplan et al. 1995). Isolation of cell lines is especially important when studying the effects of double or triple mutants, as one avoids problems caused by the effects of multiple mutations on the general physiology of the animal.

But what has the study of SFK knockouts told us about the role of these kinases in vivo? An inherent assumption that one would like to make is that members of a gene family always function within the same general signaling pathways and that the same kinase should signal in a similar pathway in different cell types. In hematopoietic cells, given the evidence that TCR signaling is impaired in $1 \mathrm{ck}^{-}$animals, BCR signaling is affected in $\mathrm{lyn}^{-} \mathrm{B}$ cells, and FceRI signaling is abrogated in lyn ${ }^{-}$ mast cells, one could postulate that SFKs play a central role in phosphorylating sequences that are common to all of these receptor types-the so-called immunoreceptor tyrosine activation motifs, or ITAM, sequences (Weiss and Littman 1994; Bolen 1995). The lack of effect on these pathways by mutations in other SFK, such as Fyn, Blk, or Fgr, may be caused by signaling through different (as yet undescribed) ITAM-related pathways in hematopoietic cells, or to redundancy. It is unlikely, however, that different SFKs would have completely identical signaling roles, as there would be little selective pressure for maintaining totally redundant kinases (Thomas 1993).

However, a central ITAM phosphorylation model does not, as yet, explain the effect of the src mutation on osteoclasts, the defective adhesion seen in $\mathrm{hck}^{-} \mathrm{fgr}^{-}$ neutrophils, or the effects of the fyn mutation on neuronal cells. Indeed, in vitro studies with $s r c^{-}$fibroblasts, neurons from $\mathrm{fyn}^{-}$and $\mathrm{src}^{-}$mice, keratinocytes from $\mathrm{fyn}^{--}$mice, as well as neutrophils and macrophages from $\mathrm{hck}^{-} \mathrm{fgr}^{-}$animals point to defects in cell adhesion as being common to most mutations. Many of these defects can be viewed as impairments in cytoskeletal rearrangements following cross-linking of surface adhesion receptors, such as integrins. Although there is a significant amount of biochemical evidence implicating SFKs in integrin-related signaling (Clark and Brugge 1995), no direct biochemical associations between any SFK and integrin receptors have been defined. Nevertheless, defective cell adhesion or integrin-related signaling events do not explain the effects on lymphocytes of the $1 c k, 1 y n$, and fyn mutations. Perhaps, as yet undefined cell-cell interactions between developing thymocytes and the thymic stroma, which depend on Lck or Fyn, may result in defective signaling through the TCR. The interaction between Fyn and Fak in $\mathrm{CD} 4{ }^{+} \mathrm{CD} 8{ }^{+}$formation supports a role for signaling pathways in cell adhesion as being critical for T-cell development. In summary, a unified role for SFK in different cells types cannot be made on the basis of the current evaluation of SFK knockout mice.

Future progress in understanding the in vivo role of SFKs will depend on our ability to further manipulate the genetic constituency of the mouse. For example, tissue-specific transgenics in which the expression of Src is enriched in osteoclasts (using a tartrate-acid resistant phosphatase promoter) is sufficient to restore osteoclast function in $\mathrm{src}^{-}$mutants, thus preventing the development of osteopetrosis (P. Schwartzberg, unpubl.). Interestingly, it appears that the kinase activity of Src is not required for the rescue of osteoclast function. Alternatively, specific mutations can be introduced into any SFK gene by homologous recombination. To directly test redundancy between different SFKs, one can attempt to switch one SFK for another, at the endogenous locus. Finally, one can test the effect of disrupting putative substrates of Src that may be important in mediating cell adhesion events. Cell lines from such Src-substrate mu* tants may become critical in future biochemical experiments. Whereas all of the Src-family kinase genes have now been disrupted, we still do not have a unifying thesis for the role of these kinases in vivo. Hence, the ultimate answers will eventually derive from continued biochemical and physiologic study of the cells and tissues from the available mutant mice.

Because this is one of the first examples in which all known members of a multigene family have been mutated in the mouse, what have these studies told us about gene families in general? One clear result is that overlapping functions between members of a multigene family are probably the norm. Clearly, there must be some selective pressure to maintain both the unique and redundant functions of individual members of a gene family. However, it is possible that the genetic "cost" of eliminating overlapping gene expression may ultimately be a selective disadvantage. Coevolution of gene families that cooperate in a single physiologic function may also occur. Thus, multiple members of a specific signaling family may have evolved to transduce signals from multiple members of a receptor family, such as surface integrins. If further studies validate adhesion-related signaling as the primary role for SFKs, the development of many adhesion receptors may explain why the SFK gene family has evolved the most members of any of the cytoplasmic tyrosine kinase families. Certainly many of these issues will be revisited in the coming years as more gene families are studied in a similar manner.

\section{Acknowledgments}

We apologize to our colleagues whose work we were unable to cite because of space constraints. We thank Giorgio Berton, Laura Fumagalli, Eric Kandel, Patricia Maness, Nicolai van Oers, Pamela Schwartzberg, Alexander Tarakovsky, and Art 
Weiss for communicating results prior to publication. We also thank Jon Cooper, Tony DeFranco, Jeff Hildebrand, Nicolai van Oers, and Harold Varmus for critical comments on the manuscript. Research in our laboratories is supported by grants from the National Institutes of Health (DK50267 to C.A.L.; HD24875/HD25326 to P.S.) and the Markey Molecular Medicine Center (P.S).

\section{References}

Abraham, K.M., S.D. Levin, J.D. Marth, K.A. Forbush, and R.M. Perlmutter. 1991. Delayed thymocyte development induced by augmented expression of p56 $6^{\text {Ick }}$. I. Exp. Med. 173: 14211432.

Achen, M.G., M. Clauss, H. Schnurch, and W. Risau. 1995. The non-receptor tyrosine kinase Lyn is localised in the developing murine blood-brain barrier. Differentiation 59: 15-24.

Anderson, S.J. and R.M. Perlmutter. 1995. A signaling pathway governing early thymocyte maturation. Immunol. Today 16: 99-105.

Anderson, S.J., S.D. Levin, and R.M. Perlmutter. 1993. Protein tyrosine kinase $\mathrm{p} 56^{\text {lck }}$ controls allelic exclusion of T-cell receptor $\beta$-chain genes. Nature 365: 552-554.

Anderson, S.M. and B. Jorgensen. 1995. Activation of Src-related tyrosine kinases by IL-3. J. Immunol. 155: 1660-1670.

Appleby, M.W., J.A. Gross, M.P. Cooke, S.D. Levin, X. Qian, and R.M. Perlmutter. 1992. Defective T cell receptor signaling in mice lacking the thymic isoform of $\mathrm{p} 59^{f y n}$. Cell 70: 751-763.

Appleby, M.W., J.D. Kerner, S. Chien, C.R. Maliszewski, S. Bondadaa, and R.M. Perlmutter. 1995. Involvement of p59 ${ }^{\text {fyn }} \mathrm{T}$ in interleukin-5 receptor signaling. I. Exp. Med. 182: 811820.

Autero, M., I. Saharinen, T. Pessa-Morikawa, M. Soula-Rothhut, C. Oetken, M. Gassmann, M. Bergman, K. Alitalo, P. Burn, C.G. Gahmberg, and T. Mustelin. 1994. Tyrosine phosphorylation of CD45 phosphotyrosine phosphatase by p $50^{\text {csk }}$ kinase creates a binding site for $\mathrm{p} 56^{\text {lck }}$ tyrosine kinase and activates the phosphatase. Mol. Cell. Biol. 14: 13081321 .

Barone, M.V. and S.A. Courtneidge. 1995. Myc but not Fos rescue of PDGF signalling block caused by kinase-inactive Src. Nature 378: 509-512.

Beggs, H., P. Soriano, and P. Maness. 1994. NCAM-dependent neurite outgrowth is inhibited in neurons from fyn-minus mice. J. Cell Biol. 127: 825-833.

Bergman, M., T. Mustelin, C. Oetken, J. Partanen, N.A. Flint, K.E. Amrein, M. Autero, P. Burn, and K. Alitalo. 1992. The human $\mathrm{p} 50^{\text {csk }}$ tyrosine kinase phosphorylates $\mathrm{p} 56^{\text {lck }}$ at Tyr505 and down regulates its catalytic activity. EMBO $J$. 11: 2919-2924.

Berton, G., L. Fumagalli, C. Laudanna, and C. Sorio. 1994. $\beta 2$ integrin-dependent protein tyrosine phosphorylation and activation of the FGR protein tyrosine kinase in human neutrophils. J. Cell. Biol. 126: 1111-1121.

Bolen, J.B. 1995. Protein tyrosine kinases in the initiation of antigen receptor signaling. Curr. Opin. Immunol. 7:306311.

Boyce, B., T. Yoneda, C. Lowe, P. Soriano, and G. Mundy. 1992. Requirement of pp60 $6{ }^{\text {c-src }}$ expression for osteoclasts to form ruffled borders and to resorb bone in mice. J. Clin. Invest. 90: $1622-1627$.

Brown, M.T. and J.A. Cooper. 1996. Regulation, substrates, and functions of Src. Biochem. Biophys. Acta Rev. Cancer (in press).

Burden-Gulley, S., H. Payne, and V. Lemmon. 1995. Growth cones are actively influenced by substrate-bound adhesion molecules. J. Neurosci. 15: 4370-4381.

Calautti, E., C. Missero, P.L. Stein, R.M. Ezzell, and G.P. Dotto. 1995. Fyn tyrosine kinase is involved in keratinocyte differentiation control. Genes \& Dev. 9: 2279-2291.

Cance, W., R. Craven, M. Bergman, L. Xu, K. Alitalo, and E. Liu. 1994. Rak, a novel nuclear tyrosine kinase expressed in epithelial cells. Cell Growth Differ. 5: 1347-1355.

Cartwright, C.A., R. Simantov, W.M. Cowan, and T. Hunter. 1988. pp $60^{c-s r c}$ expression in the developing rat brain. Proc. Natl. Acad. Sci. 85: 3348-3352.

Cheng, S.H., R. Harvey, P.C. Espino, K. Semba, T. Yamamoto, K. Toyoshima, and A.E. Smith. 1988. Peptide antibodies to the human c-fyn gene product demonstrate $\mathrm{pp} 59^{\mathrm{c}-f y n}$ is capable of complex formation with the middle-T antigen of polyoma virus. EMBO I. 7: 3845-3855.

Chow, L.M., C. Jarvis, Q. Hu, S.H. Nye, F.G. Gervais, A. Veil lette, and L.A. Matis. 1994. Ntk: A Csk-related protein-tyrosine kinase expressed in brain and T lymphocytes. Proc. Natl. Acad. Sci. 91: 4975-4979.

Clark, E.A. and J.S. Brugge. 1995. Integrins and signal transduction pathways: The road taken. Science 268: 233-239.

Cobb, B.S., M.D. Schaller, T.-H. Leu, and J.T. Parson. 1994. Stable association of $\mathrm{pp} 60^{s r c}$ and $\mathrm{p} 59^{\text {fyn }}$ with the focal adhesionassociated protein kinase tyrosine kinase pp $125^{F A K}$. Mol. Cell. Biol. 14: 147-155.

Cooke, M.P. and R.M. Perlmutter. 1989. Expression of a novel form of the fyn proto-oncogene in hematopoietic cells. New Biol. 1: 66-74.

Corey, S., A. Eguinoa, K. Puyana-Theall, J.B. Bolen, L. Cantley, F. Mollinedo, T.R. Jackson, P.T. Hawkins, and L.R. Stephens. 1993. Granulocyte macrophage-colony stimulating factor stimulates both association and activation of phosphoinositide $3 \mathrm{OH}$-kinase and Src-related tyrosine kinase(s) in human myeloid derived cells. EMBO J. 12: 26812690.

Corey, S.J., A.L. Burkhardt, J.B. Bolen, R.L. Geahlen, L.S. Tkatch, and D.J. Tweardy. 1994. Granulocyte colony-stimulating factor receptor signaling involves the formation of a three-component complex with Lyn and Syk protein-tyrosine kinases. Proc. Natl. Acad. Sci. 91: 4683-4687.

Courtneidge, S.A. and A.E. Smith. 1983. Polyoma virus transforming protein associates with the product of the c-src gene. Nature 303: 435-439.

Courtneidge, S.A., R. Dhand, D. Pilat, G.M. Twamley, M.D. Waterfield, and M.F. Roussel. 1993. Activation of Src-family kinases by colony stimulating factor- 1 , and their association with its receptor. EMBO J. 12: 943-950.

Dixon, J.E. 1995. Structure and catalytic properties of protein tyrosine phosphatases. Ann. N.Y. Acad. Sci. 766: 18-22.

Eiseman, E. and J.B. Bolen. 1992. Engagement of the high-affinity IgE receptor activates $s r c$ protein-related tyrosine kinases. Nature 355: 78-80.

Erpel, T. and S.A. Courtneidge. 1995. Src family protein tyrosine kinases and cellular signal transduction pathways. Curr. Opin. Cell. Biol. 7: 176-182.

Filvaroff, E., D.F. Stern, and G.P. Dotto. 1990. Tyrosine phosphorylation is an early and specific event involved in primary keratinocyte differentiation. Mol. Cell. Biol. 10: 1164 1173.

Gluecksohn-Schoenheimer, S. 1944. The development of normal and homozygous Brachyury (T/T) mouse embryos in the extraembryonic coelom of the chick. Proc. Natl. Acad. Sci. 30: $134-140$.

Grant, S.G., T.J. O'Dell, K.A. Karl, P.L. Stein, P. Soriano, and E.R. Kandel. 1992. Impaired long-term potentiation, spatial 
learning, and hippocampal development in Fyn mutant mice. Science 258: 1903-1910.

Grant, S.G., K.A. Karl, M.A. Kiebler, and E.R. Kandel. 1995. Focal adhesion kinase in the brain: Novel subcellular localization and specific regulation by Fyn tyrosine kinase in mutant mice. Genes \& Dev. 9: 1909-1921.

Green, M.C. 1989. Catalog of mutant genes and polymorphic loci. In Genetic variants and strain of the laboratory mouse (ed. M.F. Lyon and A.G. Searle), pp. 12-403. Oxford University Press, Oxford, UK.

Gupta, S., A. Weiss, G. Kumar, S. Wang, and A. Nel. 1994. The T-cell antigen receptor utilizes Lck, Raf-1, and MEK-1 for activating mitogen-activated protein kinase. Evidence for the existence of a second protein kinase C-dependent pathway in an Lck-negative Jurkat cell mutant. J. Biol. Chem. 269: 17349-17357.

Guy, C.T., R.D. Cardiff, and W.J. Muller. 1992. Induction of mammary tumors by expression of polyomavirus middle $T$ oncogene: A transgenic mouse model for metastatic disease. Mol. Cell. Biol. 12: 954-961.

Guy, C.T., S.K. Muthuswamy, R.D. Cardiff, P. Soriano, and W.J. Muller. 1994. Activation of the c-Src tyrosine kinase is required for the induction of mammary tumors in transgenic mice. Genes \& Dev. 8: 23-32.

Hamada, F., M. Aoki, T. Akiyama, and K. Toyoshima. 1993. Association of immunoglobulin G Fc receptor II with Srclike protein-tyrosine kinase Fgr in neutrophils. Proc. Natl. Acad. Sci. 90: 6305-6309.

Hemesath, T., E. Steingrimsson, G. McGill, M. Hansen, J. Vaught, C. Hodgkinson, H. Arnheiter, N. Copeland, N. Jenkins, and D. Fisher. 1994. Microphthalmia, a critical factor in melanocyte development, defines a discrete transcription factor family. Genes \& Dev. 8: 2770-2780.

Hennings, H., D. Michael, C. Cheng, P. Steinert, K. Holbrook, and S.H. Yuspa. 1990. Calcium regulation of growth and differentiation of mouse epidermal cells in culture. Cell 19: $245-254$.

Hibbs, M.L., D.M. Tarlinton, J. Armes, D. Grail, G. Hodgson, R. Maglitto, S.A. Stacker, and A.R. Dunn. 1995. Multiple defects in the immune system of Lyn-deficient mice, culminating in autoimmune disease. Cell 83: 301-311.

Horne, W., L. Neff, D. Chatterjee, A. Lomri, I. Levy, and R. Baron. 1992. Osteoclasts express high levels of $p p 60^{\text {c-src }}$ in association with intracellular membranes. I. Cell. Biol. 119: 1003-1013.

Howell, B.W. and J.A. Cooper. 1994. Csk suppression of Src involves movement of Csk to sites of Src activity. Mol. Cell. Biol. 14: 5402-5411.

Hunter, S., M.M. Huang, Z.K. Indik, and A.D. Schreiber. 1993. FcyRIIA-mediated phagocytosis and receptor phosphorylation in cells deficient in the protein tyrosine kinase Src. Exp. Hematol. 21: 1492-1497.

Ignelzi, M.A., D.R. Miller, P. Soriano, and P.F. Maness. 1994. Impaired neurite outgrowth of Src-minus neurons on the cell adhesion molecule L1. Neuron 12: 873-884.

Ilic, D., Y. Furuta, S. Kanazawa, N. Takeda, K. Sobue, N. Nakatsuji, S. Nomura, J. Fujimoto, M. Okada, T. Yamamoto, and S. Aizawa. 1995. Reduced cell motility and enhanced focal adhesion contact formation in cells from FAK-deficient mice. Nature 377: 539-544.

Imamoto, A. and P. Soriano. 1993. Disruption of the csk gene, encoding a negative regulator of Src family tyrosine kinases, leads to neural tube defects and embryonic lethality in mice. Cell 73: 1117-1124.

Johnson, R.S., B.M. Spiegelman, and V. Papaioannou. 1992. Pleiotropic effects of a null mutation in the c-fos proto- oncogene. Cell 71: 577-586.

Kanazawa, S., D. Ilic, M. Hashiyama, T. Noumura, T. Yamamoto, T. Suda, and S. Aizawa. 1996. p59 $9^{f y n}$-p125 $5^{\text {Fak }}$ cooperation in development of $\mathrm{CD} 4{ }^{+} \mathrm{CD} 8{ }^{+}$thymocytes. Blood 87: 865-870.

Kaplan, K.B., J.R. Swedlow, H.E. Varmus, and D.O. Morgan. 1992. Association of p60 $0^{\text {c.src }}$ with endosomal membranes in mammalian fibroblasts. I. Cell. Biol. 118: 321-333.

Kaplan, K.B., K.B. Bibbins, J.R. Swedlow, M. Arnaud, D.O. Morgan, and H.E. Varmus. 1994. Association of the amino-terminal half of $\mathrm{c}$-Src with focal adhesions alters their properties and is regulated by phosphorylation of tyrosine 527 . $E M B O$ /. 13: 4745-4756.

Kaplan, K.B., J.R. Swedlow, D.O. Morgan, and H.E. Varmus. 1995. c-Src enhances the spreading of $\mathrm{src}^{-1-}$ fibroblasts on fibronectin by a kinase-independent mechanism. Genes \& Dev. 9: 1505-1517.

Kiefer, F., I. Anhauser, P. Soriano, A. Aguzzi, S.A. Courtneidge, and E.F. Wagner. 1994. Endothelial cell transformation by polyomavirus middle $\mathrm{T}$ antigen in mice lacking Src-related kinases. Curr. Biol. 4: 100-109.

Klages, S., D. Adam, K. Class, J. Fargnoli, J.B. Bolen, and R.C. Penhallow. 1994. Ctk: A protein-tyrosine kinase related to Csk that defines an enzyme family. Proc. Natl. Acad. Sci. 91: 2597-2601.

Kornbluth, S., M. Sudol, and H. Hanafusa. 1987. Association of the polyomavirus middle $\mathrm{T}$ antigen with c-yes protein. $\mathrm{Na}$ ture 325: 171-173.

Kypta, R.M., Y. Goldber, E.T. Ulug, and S.A. Courtneidge. 1990. Association between the PDGF receptor and members of the Src-family of tyrosine kinases. Cell 62: 481-492.

Lancki, D.W., P. Fields, D. Qian, and F.W. Fitch. 1995a. Induction of lytic pathways in T cell clones derived from wild-type or protein tyrosine kinase Fyn mutant mice. Immunol. Rev. 146: $117-144$.

Lancki, D.W., D. Qian, P. Fields, T. Gajewski, and F.W. Fitch 1995b. Differential requirement for protein tyrosine kinase Fyn in the functional activation of antigen-specific $\mathrm{T}$ lymphocyte clones through the TCR or Thy-1. I. Immunol. 154: 4363-4370.

Levin, S.D., S.J. Anderson, K.A. Forbush, and R.M. Perlmutter. 1993. A dominant-negative transgene defines a role for p56 ${ }^{\text {lck }}$ in thymopoiesis. EMBO J. 12: 1671-1680.

Lock, P., S. Ralph, E. Stanley, I. Boulet, R. Ramsay, and A.R Dunn. 1991. Two isoforms of murine Hck, generated by utilization of alternative translational initiation codons, ex hibit different patterns of subcellular localization. Mol. Cell. Biol. 11: 4363-4370.

Lowe, C., T. Yoneda, B.F. Boyce, H. Chen, G.R. Mundy, and P. Soriano. 1993. Osteopetrosis in Src-deficient mice is due to an autonomous defect of osteoclasts. Proc. Natl. Acad. Sci. 90: 4485-4489.

Lowell, C.A., P. Soriano, and H.E. Varmus. 1994. Functional overlap in the $s r c$ gene family: Inactivation of hck and $f g r$ impairs natural immunity. Genes \& Dev. 8: 387-398.

Lowell, C.A., L. Fumagalli, and G. Berton. 1996a. Deficiency of Src-family kinases p59/61 ${ }^{h c k}$ and p58 $8^{\mathrm{c}-f g r}$ results in defective adhesion-dependent neutrophil functions. I. Cell Biol. 133: 895-910.

Lowell, C.A., M. Niwa, P. Soriano, and H.E. Varmus. 1996b. Deficiency of the Hck and Src tyrosine kinases results in extreme levels of extramedullary hematopoiesis. Blood 87: 1780-1792.

Markland, W.D. and A.E. Smith. 1987. Mutants of polyomavirus middle-T antigen. Biochim. Biophys. Acta 907: 299-321.

Martinez, R., B. Mathey-Prevot, A. Bernards, and D. Baltimore. 
1987. Neuronal pp $60^{c-s r c}$ contains a six-amino acid insertion relative to its non-neuronal counterpart. Science 237: 411415.

Molina, T.J., K. Kishihara, D.P. Siderovski, W. van Ewijk, A. Narendran, E. Timms, A. Wakeham, C.J. Paige, K.U. Hartmann, A. Veillette, and T.W. Mak. 1992. Profound block in thymocyte development in mice lacking $\mathrm{p} 56^{\mathrm{lck}}$. Nature 357: 161-164.

Molina, T.J., M.F. Bachmann, T.M. Kundig, R.M. Zinkernagel, and T.W. Mak. 1993. Peripheral T cells in mice lacking p5 $6^{l c k}$ do not express significant antiviral effector functions. I. Immunol. 151: 699-706.

Mombaerts, P., S.J. Anderson, R.M. Perlmutter, T.W. Mak, and S. Tonegawa. 1994. An activated lck transgene promotes thymocyte development in RAG-1 mutant mice. Immunity 1: 261-267.

Nada, S., M. Okada, A. MacAuley, J.A. Cooper, and H. Nakagawa. 1991. Cloning of a complementary DNA for a proteintyrosine kinase that specifically phosphorylates a negative regulatory site of $\mathrm{p} 60^{\mathrm{c}-s r c}$. Nature 351: 69-72.

Nada, S., T. Yagi, H. Takeda, T. Tokunaga, H. Nakagawa, Y. Ikawa, M. Okada, and S. Aizawa. 1993. Constitutive activation of Src family kinases in mouse embryos that lack Csk. Cell 73: 1125-1135.

Nada, S., M. Okada, S. Aizawa, and H. Nakagawa. 1994. Identification of major tyrosine-phosphorylated proteins in Cskdeficient cells. Oncogene 9: 3571-3578.

Nishizumi, H., I. Taniuchi, Y. Yamanashi, D. Kitamura, D. Ilic, S. Mori, T. Watanabe, and T. Yamamoto. 1995. Impaired proliferation of peripheral B cells and indication of autoimmune disease in lyn-deficient mice. Immunity 3: 549-560.

Penhallow, R.C., K. Class, H. Sonoda, J.B. Bolen, and R.B. Rowley. 1995. Temporal activation of nontransmembrane protein-tyrosine kinases following mast cell Fc $\in R I$ engagement. J. Biol. Chem. 270: 23362-23365.

Pyper, J.M. and J.B. Bolen. 1990. Identification of a novel neuronal C-SRC exon expressed in human brain. Mol. Cell. Biol. 10: 2035-2040.

Resh, M.D. 1994. Myristylation and palmitylation of Src family members: The fats of the matter. Cell 76: 411-413.

Richardson, A. and I. Parsons. 1995. Signal transduction through integrins: A central role for focal adhesion kinase? BioEssays 17: 229-236.

Robbins, S.M., N.A. Quintrell, and J.M. Bishop. 1995. Myristoylation and differential palmitoylation of the HCK proteintyrosine kinases govern their attachment to membranes and association with caveolae. Mol. Cell. Biol. 15: 3507-3515.

Rohrschneider, L.R. 1980. Adhesion plaques of Rous sarcoma virus-transformed cells contain the Src gene product. Proc. Natl. Acad. Sci. 77: 3514-3518.

Ross, C.A., G.E. Wright, M.D. Resh, R.C. Pearson, and S.H. Snyder. 1988. Brain-specific src oncogene mRNA mapped in rat brain by in situ hybridization. Proc. Natl. Acad. Sci. 85: $9831-9835$.

Sillman, A.L. and J.G. Monroe. 1994. Surface IgM-stimulated proliferation, inositol phospholipid hydrolysis, $\mathrm{Ca}_{2}{ }^{+}$flux, and tyrosine phosphorylation are not altered in $\mathrm{B}$ cells from p5 $9^{f y n^{-1}}$ mice. J. Leukoc. Biol. 56: 812-816.

Soriano, P., C. Montgomery, R. Geske, and A. Bradley. 1991. Targeted disruption of the c-src proto-oncogene leads to osteopetrosis in mice. Cell 64: 693-702.

Stanley, E., S. Ralph, S. McEwen, I. Boulet, D.A. Holtzman, P. Lock, and A.R. Dunn. 1991. Alternatively spliced murine lyn mRNAs code distinct proteins. Mol. Cell. Biol. 11: 3399-3406.

Stefanova, I., M.L. Corcoran, E.M. Horak, L.M. Wahl, J.B. Bolen, and I.D. Horak. 1993. Lipopolysaccharide induces activation of CD14-associated protein tyrosine kinase $\mathrm{p} 53 / 56^{\mathrm{lyn}}$. $J$. Biol. Chem. 268: 20725-20728.

Stehelin, D., H.E. Varmus, J.M. Bishop, and P.K. Vogt. 1976. DNA related to the transforming gene(s) of avian sarcoma viruses is present in normal avian DNA. Nature 260: 170173.

Stein, P.L., H.M. Lee, S. Rich, and P. Soriano. 1992. pp59 $9^{f y n}$ mutant mice display differential signaling in thymocytes and peripheral $\mathrm{T}$ cells. Cell 70: 741-750.

Stein, P.L., H. Vogel, and P. Soriano. 1994. Combined deficiencies of Src, Fyn, and Yes tyrosine kinases in mutant mice. Genes \& Dev. 8: 1999-2007.

Sudol, M., A. Alvarez-Buylla, and H. Hanafusa. 1988. Differential developmental expression of cellular Yes and cellular Src proteins in cerebellum. Oncogene Res. 2: 345-355.

Sudol, M., H. Greulich, L. Newman, A. Sarkar, J. Sukegawa, and T. Yamamoto. 1993. A novel Yes-related kinase, Yrk, is expressed at elevated levels in neural and hematopoietic tissues. Oncogene 8: 823-831.

Sugrue, M., J. Brugge, D. Marshak, P. Greengard, and E. Gustafson. 1990. Immunocytochemical localization of the neuronspecific form of the c-src gene product, $\mathrm{pp} 60^{\mathrm{c}-\mathrm{srcl}+1}$, in rat brain. I. Neuroscience 10: 2513-2527.

Superti-Furga, G. 1995. Regulation of the Src protein tyrosine kinase. FEBS Lett. 369: 62-66.

Thomas, J.E., P. Soriano, and J.S. Brugge. 1991. Phosphorylation of c-Src on tyrosine 527 by another protein tyrosine kinase. Science 254: 568-571.

Thomas, I.E., A. Aguzzi, P. Soriano, E.F. Wagner, and J.S. Brugge. 1993. Induction of tumor formation and cell transformation by polyoma middle $\mathrm{T}$ antigen in the absence of Src. Oncogene 8: 2521-2529.

Thomas, J.H. 1993. Thinking about genetic redundancy. Trends Genet. 9: 395-399.

Thomas, S., P. Soriano and A. Imamoto. 1995. Specific and redundant roles of Src and Fyn in organizing the cytoskeleton. Nature 376: 267-271.

Tsygankov, A. and J. Bolen. 1993. The Src family of tyrosine protein kinases in hemopoietic signal transduction. Stem Cells 11: 371-380.

Twamley-Stein, G.M, R. Pepperkok, W. Ansorge, and S.A. Courtneidge. 1993. The Src family tyrosine kinases are required for platelet-derived growth factor-mediated signal transduction in NIH 3T3 cells. Proc. Natl. Acad. Sci. 90: 7696-7700.

Umemori, H., A. Wanaka, H. Kato, M. Takeuchi, M. Tohyama, and T. Yamamoto. 1992. Specific expressions of Fyn and Lyn, lymphocyte antigen receptor-associated tyrosine kinases, in the central nervous system. Brain Res. Mol. Brain Res. 16: 303-310.

Umemori, H., S. Sato, T. Yagi, S. Aizawa, and T. Yamamoto. 1994. Initial events of myelination involve Fyn tyrosine kinase signalling. Nature 367: 572-576.

Veillette, A. and D. Davidson. 1992. Src-related protein tyrosine kinases and T-cell receptor signalling. Trends Genet. 8: 6166.

Wallace, V.A., K. Kawai, C.N. Levelt, K. Kishihara, T. Molina, E. Timms, H. Pircher, J. Penninger, P.S. Ohashi, K. Eichmann, and T.W. Mak. 1995. T lymphocyte development in p56 $6^{\text {lck }}$ deficient mice: Allelic exclusion of the TcR $\beta$-locus is incomplete but thymocyte development is not restored by TcR $\beta$ or TcR $\alpha \beta$ transgenes. Eur. I. Immunol. 25: 1312-1318.

Wang, A.V., P.R. Scholl, and R.S. Geha. 1994. Physical and functional association of the high affinity immunoglobulin $G$ receptor (Fc $\gamma \mathrm{RI}$ ) with the kinases Hck and Lyn. I. Exp. Med. 
180: $1165-1170$.

Wang, Z.-Q., C. Ovitt, A.E. Grigoriadis, U. Möhle-Steinlein, U. Rüther, and E.F. Wagner. 1992. Bone and haematopoietic defects in mice lacking c-fos. Nature 360: 741-745.

Wechsler, R.J. and J.G. Monroe. 1995. Immature B lymphocytes are deficient in expression of the $s r c$-family kinases p59fyn and p55 ${ }^{f g r}$. J. Immunol. 154: 1919-1929.

Weil, R. and A. Veillette. 1996. Signal transduction by the lymphocyte-specific tyrosine protein kinase p56lck. Curr. Top. Microbiol. Immunol. 205: 63-87.

Weiss, A. 1993. T cell antigen receptor signal transduction: A tale of tails and cytoplasmic protein-tyrosine kinases. Cell 73: $209-212$.

Weiss, A. and D.R. Littman. 1994. Signal transduction by lymphocyte antigen receptors. Cell 76: 263-274.

Wen, T., L. Zhang, S.K. Kung, T.J. Molina, R.G. Miller, and T.W. Mak. 1995. Allo-skin graft rejection, tumor rejection and natural killer activity in mice lacking p56 ${ }^{\text {Ick }}$. Eur. I. Immunol. 25: 3155-3159.

Wiktor-Jedrzejczak, W., A. Bartocci, A. Ferrante, A. Ahmed-Ansari, K. Sell, J. Pollard, and E. Stanley. 1990. Total absence of colony-stimulating factor 1 in the macrophage-deficient osteopetrotic (op/op) mouse. Proc. Natl. Acad. Sci. 87: 48284832.

Williams, E., J. Furness, F. Walsh, and P. Doherty. 1994. Activation of the FGF receptor underlies neurite outgrowth stimulated by L1, N-CAM, and N-cadherin. Neuron 13: 583-594.

Williams, R.L., S.A. Courtneidge, and E.F. Wagner. 1988. Embryonic lethalies and endothelial tumors in chimeric mice expressing polyoma virus middle $\mathrm{T}$ oncogene. Cell 52: 121131.

Wu, H. and J. Parsons. 1993. Cortactin, an 80/85-kilodalton pp $60^{\text {src }}$ substrate, is a filamentous actin-binding protein enriched in the cell cortex. J. Cell. Biol. 120: 1417-1426.

Xu, H. and D.R. Littman. 1993. A kinase-independent function of Lck in potentiating antigen-specific $\mathrm{T}$ cell activation. Cell 74: 633-643.

Yagi, 'T., S. Aizawa, T. Tokunaga, Y. Shigetani, N. Takeda, and Y. Ikawa. 1993a. A role for Fyn tyrosine kinase in the suckling behaviour of neonatal mice. Nature 366: 742-745.

Yagi, T., Y. Shigetani, N. Okado, T. Tokunaga, Y. Ikawa, and S. Aizawa. 1993b. Regional localization of Fyn in adult brain: Studies with mice in which fyn gene was replaced by lacz. Oncogene 8: 3343-3351.

Yan, S.R., L. Fumagalli, and G. Berton. 1995. Activation of p58 $8^{\mathrm{c}-}$ fgr and p53/56 $6^{\text {Iyn }}$ in adherent human neutrophils: Evidence for a role of divalent cations in regulation of neutrophil adhesion and protein tyrosine kinase activities. I. Inflammation 45: 297-331.

Yasunaga, M., T. Yagi, N. Hanzawa, M. Yasuda, Y. Yamanashi, T. Yamamoto, S. Aizawa, Y. Miyauchi, and S. Nishikawa. 1996. Involvement of Fyn tyrosine kinase in progression of cytokinesis of B lymphocyte progenitor. J. Cell. Biol. 132: 91-99.

Yi, T., J.B. Bolen, and J.N. Ihle. 1991. Hematopoietic cells express two forms of Lyn kinase differing by 21 amino acids in the amino terminus. Mol. Cell. Biol. 11: 2391-2398.

Yoshida, H., S.-I. Hayashi, T. Kunisada, M. Ogawa, S. Nishikawa, H. Okumura, T. Sudo, L.D. Shults, and S.-I. Nishikawa. 1990. The murine mutation osteopetrosis is in the coding region of the macrophage colony stimulating factor gene. Nature 345: 442-444. 


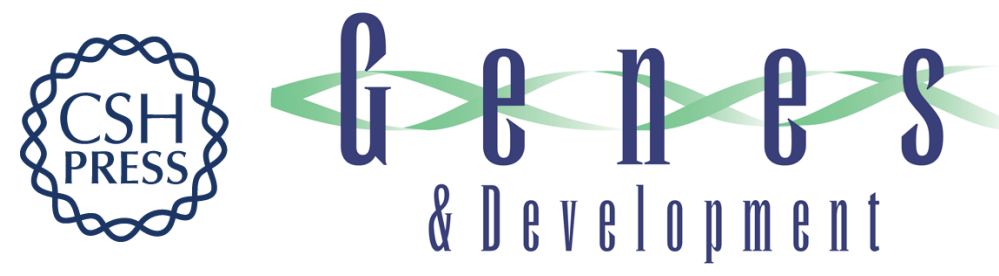

\section{Knockouts of Src-family kinases: stiff bones, wimpy T cells, and bad memories.}

C A Lowell and P Soriano

Genes Dev. 1996, 10:

Access the most recent version at doi:10.1101/gad.10.15.1845

References This article cites 119 articles, 54 of which can be accessed free at:

http://genesdev.cshlp.org/content/10/15/1845.full.html\#ref-list-1

License

Email Alerting

Service

Receive free email alerts when new articles cite this article - sign up in the box at the top right corner of the article or click here.

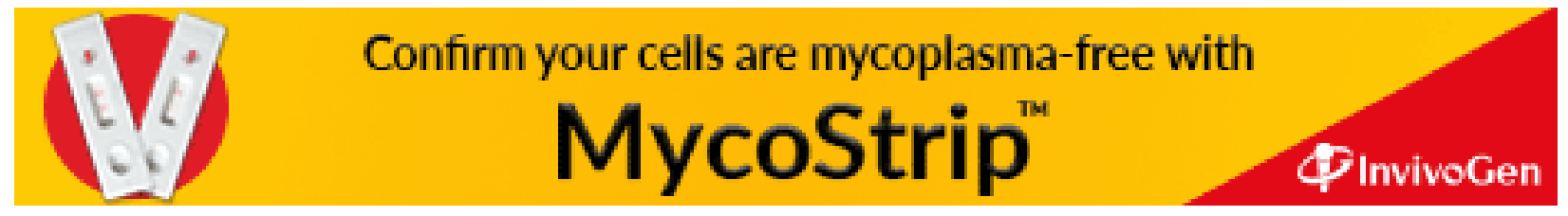

